\title{
The dilemma of patient age
} in decision-making for extracorporeal life support in cardiopulmonary resuscitation

\author{
Roberto Lorusso ${ }^{1 *}$, Alain Cariou ${ }^{2}$ and Hans Flaatten ${ }^{3}$
}

(C) 2018 Springer-Verlag GmbH Germany, part of Springer Nature

\section{"Time is precious, but truth is more precious than time" Benjamin Disraeli}

Consideration of patient age in the decision-making for starting extracorporeal life support (ECLS) has long been recognised as a dilemma and remains controversial [1-8]. Providing ECLS is resource intensive and a complicated post-implementation course, or eventually proven to be futile, is not uncommon. The institution of temporary mechanical circulatory support is however growing, particularly in the subgroup of patients above 80 years of age (very old), with a close to doubling in use from 2004-7 to 2008-11 year-periods [9]. This demonstrates that ECLS is increasingly considered also for patients previously deemed not eligible for such aggressive treatments. Furthermore, admission of elderly patients to intensive care units for advanced treatments also seems to be increasing $[10,11]$. Hence, as a result of recent advances in managing critical illness, advanced age is not considered a contraindication per se to advanced critical care therapies including temporary mechanical circulatory support. The question is, of course, to which extent and, indeed, whether we have actual age limits?

$\mathrm{Yu}$ and associates have addressed this controversial issue in their clinical study of in-hospital (IHCA) and out-of-hospital (OHCA) cardiac arrest patients undergoing ECLS as part of cardiopulmonary resuscitation, commonly referred to as ECPR [12].

Obviously, cardiac arrest compared to cardiogenic shock is more challenging and the injury imposed by

\footnotetext{
*Correspondence: roberto.lorussobs@gmail.com

${ }^{1}$ Cardio-Thoracic Surgery Department - Heart \& Vascular Centre, Maastricht University Medical Center, Maastricht, The Netherlands Full author information is available at the end of the article
}

no-flow and low-flow conditions of the former significantly worse. In addition, cardiac arrest patients have rarely been screened for agreed contraindications to advanced haemodynamic support.

The institution of ECPR for refractory cardiac arrest is usually meant as a bridge to recovery, and in the very old patients this may be the only objective, since more advanced treatment modalities such as heart transplantation or use of durable left ventricular assist devices are at present not a real option. The critical question is, of course, whether these patients have sustained irreversible injury during the cardiac arrest with little or no possibility of recovery. Is there a realistic possibility of an uncomplicated, time- and resource-limited approach in this scenario? The findings of $\mathrm{Yu}$ and associates confirm the ominous prognosis of ECPR in the very old patients when a certain time to mechanical support (60 $\mathrm{min})$ has been passed. Age, as negative determinant of ECLS outcome, has been highlighted by previous investigations [1-8], although overall outcomes have never been sufficiently dismal to disqualify the very old patients of access to ECLS, particularly in a cardiac arrest scenario [4]. Indeed, an unfavourable prognosis when ECPR is started after an hour of resuscitation has been previously reported $[13,14]$ and the study of Yu and associates confirms previous investigations, underlining the strict association of ECPR timing and patient age with regards to ultimate outcome. The time to ECPR plays a critical role irrespective of patient age, with few survivors even in the young patient group after an hour of resuscitation efforts. If time is precious, this is particularly true for the elderly. The relevance of "door-to-support" in cardiogenic shock has been recently highlighted [15] but might be more critical in elderly patients. The decision to proceed 
Table 1 Factors to be assessed when managing ECPR in elderly patients

\begin{tabular}{|c|c|}
\hline PRO & CON \\
\hline Very short no-flow time ( $<5 \mathrm{~min}$ ) and immediate CPR by bystanders & $\begin{array}{l}\text { Terminal phase of underlying illnesses and/or severe comorbidities (brain, } \\
\text { renal, liver, lung) }\end{array}$ \\
\hline $\begin{array}{l}\text { Limited low-flow time (<60 min) and quick access to ECLS implant (short } \\
\text { door-to-support time) }\end{array}$ & $\begin{array}{l}\text { No rapidly reversible cause of cardiac arrest and/or no possibility of cardiac } \\
\text { recovery }\end{array}$ \\
\hline $\begin{array}{l}\text { Potential for rapid cardiac recovery (within 3-4 days) (recognized and } \\
\text { treatable cause, like AMI) }\end{array}$ & $\begin{array}{l}\text { Patient and family opinion (about prolonged support, complications man- } \\
\text { agement, cessation, further treatment and investigations, procedures) }\end{array}$ \\
\hline Low-threshold for additional intervention and/or ECLS cessation & Severe and profound organ hypoxemia (lactate $>6 \mathrm{mmol} / \mathrm{L}$ or $\mathrm{pH}<7.0$ ) \\
\hline $\begin{array}{l}\text { Local attitude and resource allocation encouraging quickly decision- } \\
\text { oriented (to start or to abstain) }\end{array}$ & $\begin{array}{l}\text { Brain and neurological examination shortly after ECLS implant and there- } \\
\text { after }\end{array}$ \\
\hline
\end{tabular}

$E C P R$ extra-corporeal cardiopulmonary resuscitation, $I C U$ intensive care unit

to ECPR when IHCA occurs might be less challenging, since the peri-arrest conditions are certainly more favourable, particularly in terms of having patient information available, the quality of cardiopulmonary resuscitation and the time to intervention. Notwithstanding, we definitely need more data and insights mainly for OHCA, and in particular better outcome data in regards to heartrelated quality of life and cognition in the very old patient group. The benefit of post-resuscitation care should also be assessed in older patients, since few data are available at this time for management [16].

At present we know that in some patients, and irrespective of age, ECPR might be beneficial in refractory cardiac arrest. The factors invariably associated with positive or negative outcome, however, are only partially known. The study by $\mathrm{Yu}$ and associates provides a small, but relevant contribution to resolving this knowledge gap and stimulates further efforts to avoid futile interventions that might negatively impact on mechanical circulatory support programs. Neurological complications on ECLS are often catastrophic with poor outcomes and once manifest should prompt careful consideration of withdrawing ECLS based on the very limited potential of recovery, particularly in the elderly patients. Other factors may play a role in the decision-making for ECPR in the very old patient, including geographical, religious and financial reasons. The study of $\mathrm{Yu}$ and colleagues tells us that time is always important, particularly for the elderly patients, but recognition of the diversity of local approaches as well as the limit of therapeutic intervention is most likely more important (Table 1 ). We need to fully understand treatment capacity and shortcomings. This is a long and perilous road, and future studies will help to elucidate what we can or cannot achieve within current ECPR programs. Team-based action and treatment in medicine is exploding, and this may reduce the time to intervention and bring more elderly patients in front of Shock Team examination, thereby increasing the number of difficult and controversial cases. We need more insights and data, other than time-related predictors, to understand if we should proceed or stop ECPR based on age criteria.

\section{Author details \\ ${ }^{1}$ Cardio-Thoracic Surgery Department - Heart \& Vascular Centre, Maastricht University Medical Center, Maastricht, The Netherlands. ${ }^{2}$ Medical Intensive Care Unit, Cochin University Hospital (APHP) and Paris Descartes University, Paris, France. ${ }^{3}$ Department of Clinical Medicine, University of Bergen/Hauke- land University Hospital, Bergen, Norway.}

Received: 8 November 2018 Accepted: 3 December 2018

Published online: 7 December 2018

\section{References}

1. Lorusso R, Gelsomino S, Parise O, Mendiratta P, Prodhan P, Rycus P, MacLaren G, Brogan TV, Chen YS, Maessen J, Hou X, Thiagarajan RR (2017) Veno-arterial extracorporeal membrane oxygenation for refractory cardiogenic shock in elderly patients: trends in application and outcome from the Extracorporeal Life Support Organization (ELSO) registry. Ann Thorac Surg 104:62-69

2. Mendiratta P, Wei JY, Gomez A, Podrazik P, Riggs AT, Rycus P, Gossett J, Prodhan P (2013) Cardiopulmonary resuscitation requiring extracorporeal membrane oxygenation in the elderly: a review of the Extracorporeal Life Support Organization registry. ASAIO J 59:211-215

3. Saito S, Nakatani T, Kobayashi J, Tagusari O, Bando K, Niwaya K, Nakajima H, Miyazaki S, Yagihara T, Kitamura S (2007) Is extracorporeal life support contraindicated in elderly patients? Ann Thorac Surg 87:140-145

4. Smith C, Bellomo R, Raman JS, Matalanis G, Rosalion A, Buckmaster J, Hart G, Silvester W, Gutteridge GA, Smith B, Doolan L, Buxton BF (2001) An extracorporeal membrane oxygenation-based approach to cardiogenic shock in an older population. Ann Thorac Surg 71:1421-1427

5. Narotski DL, Mosca ML, Mochari-Greenberg H, Beck J, Liao M, Mongero L, Bacchetta M (2016) Short-term and longer-term survival after veno-arterial extracorporeal membrane oxygenation in an adult patient population: does older age matter? Perfusion 31:366-375

6. Saxena P, Neal J, Joyce LD, Greason KL, Schaff HV, Guru P, Shi WY, Burkhart H, Li Z, Oliver WC, Pike RB, Haile DT, Schears GJ (2015) Extracorporeal membrane oxygenation support in postcardiotomy elderly patients: the Mayo Clinic experience. Ann Thorac Surg 99:2053-2060

7. Atluri P, Goldstone AB, Kobrin DM, Cohen JE, MacArthur JW, Howard JL, Jessup ML, Rame JE, Acker MA, Woo YJ (2013) Ventricular assist device implant in the elderly is associated with increased, but respectable risk: a multi-institutional study. Ann Thorac Surg 96:141-147

8. Pontallier M, Demondion P, Lebreton G, Golmard JL, Leprince P (2017) Experience with extracorporeal life support for cardiogenic shock in the older population than 70 years of age. ASAIO J 63:279-284 
9. Stretch R, Sauer CM, Yuh DD, Bonde P (2014) National trends in the utilization of short-term mechanical circulatory support: incidence, outcomes, and cost analysis. J Am Coll Cardiol 64:1407-1415

10. MacLaren $\mathrm{G}$ (2015) Rage, rage against the dying of the light? Intensive care for the very elderly. Minerva Anesthesiol 81:709-710

11. Flaatten H, Garrouste-Orgeas M (2015) The very old ICU patient: a neverending story. Intensive Care Med 41(11):1996-1998

12. Yu HY, Wang CH, Chi NH, Huang SC, Chou HW, Chou NK, Chen YS (2018) Effect of interplay between age and low-flow duration on neurological outcomes of extracorporeal cardiopulmonary resuscitation. Intensive Care Med (in press)

13. Massetti M, Tasle M, Le Page O, Deredec R, Babatasi G, Buklas D, Thuadet S, Charbonneau P, Hamon M, Grollier G, Gerard JL, Khayat A (2005) Back from irreversibility: extracorporeal life support for prolonged cardiac arrest. Ann Thorac Surg 79:178-184

14. Han SJ, Kim HS, Choi SS et al (2015) Predictors of survival following extracorporeal cardiopulmonary resuscitation in patients with acute myocardial infarction-complicated refractory cardiac arrest in the emergency department: a retrospective study. J Cardio Thorac Surg 10:23

15. Kapur NK, Davilla CD (2017) Timing, timing, timing: the emerging concept of "door-to support" time for cardiogenic shock. Eur Heart J 38:3532-3534

16. Aissaoui N, Bougouin W, Dumas F et al (2018) Age and benefit of early coronary angiography after out-of-hospital cardiac arrest in patients presenting with shockable rhythm: insights from the Sudden Death Expertise Center Registry. Resuscitation 128:126-131 